\title{
Ischemic Preconditioning Stimulates Sodium and Proton Transport in Isolated Rat Hearts
}

\author{
Ravichandran Ramasamy, ${ }^{\star}$ Hong Liu, ${ }^{\ddagger}$ Steven Anderson, ${ }^{\ddagger}$ Jennifer Lundmark, ${ }^{\star}$ and Saul Schaefer ${ }^{*}$ \\ $*$ Department of Internal Medicine, Division of Cardiovascular Medicine, and ${ }^{\ddagger}$ Department of Human Physiology, University of \\ California, Davis, California 95616
}

\begin{abstract}
One or more brief periods of ischemia, termed preconditioning, dramatically limits infarct size and reduces intracellular acidosis during subsequent ischemia, potentially via enhanced sarcolemmal proton efflux mechanisms. To test the hypothesis that preconditioning increases the functional activity of sodium-dependent proton efflux pathways, isolated rat hearts were subjected to $30 \mathrm{~min}$ of global ischemia with or without preconditioning. Intracellular sodium $\left(\mathbf{N a}_{\mathbf{i}}\right)$ was assessed using ${ }^{23} \mathrm{Na}$ magnetic resonance spectroscopy, and the activity of the $\mathrm{Na}-\mathrm{H}$ exchanger and $\mathrm{Na}-\mathrm{K}-2 \mathrm{Cl}$ cotransporter was measured by transiently exposing the hearts to an acid load $\left(\mathrm{NH}_{4} \mathrm{Cl}\right.$ washout $)$. Creatine kinase release was reduced by greater than $60 \%$ in the preconditioned hearts $(P<0.05)$ and was associated with improved functional recovery on reperfusion. Preconditioning increased $\mathrm{Na}_{i}$ by $6.24 \pm 2.04 \mathrm{U}$, resulting in a significantly higher level of $\mathrm{Na}_{i}$ before ischemia than in the control hearts. $\mathrm{Na}_{\mathrm{i}}$ increased significantly at the onset of ischemia $(8.48 \pm 1.21$ vs. $2.57 \pm 0.81 \mathrm{U}$, preconditioned vs. control hearts; $P<0.01$ ). Preconditioning did not reduce $\mathrm{Na}_{\mathbf{i}}$ accumulation during ischemia, but the decline in $\mathrm{Na}_{\mathrm{i}}$ during the first $5 \mathrm{~min}$ of reperfusion was significantly greater in the preconditioned than in the control hearts $(13.48 \pm 1.73$ vs. $2.54 \pm 0.41 \mathrm{U} ; P$ $<0.001$ ). Exposure of preconditioned hearts to ethylisopropylamiloride or bumetanide in the last reperfusion period limited in the increase in $\mathrm{Na}_{\mathbf{i}}$ during ischemia and reduced the beneficial effects of preconditioning. After the $\mathrm{NH}_{4} \mathrm{Cl}$ prepulse, preconditioned hearts acidified significantly more than control hearts and had significantly more rapid recovery of pH (preconditioned, $\Delta \mathrm{pH}=0.35 \pm 0.04 \mathrm{U}$ over $5 \mathrm{~min}$; control, $\Delta \mathrm{pH}=0.15 \pm 0.02 \mathrm{U}$ over $5 \mathrm{~min}$ ). This rapid $\mathrm{pH}$ recovery was not affected by inhibition of the $\mathrm{Na}-\mathrm{K}-2 \mathrm{Cl}$ cotransporter but was abolished by inhibition of the $\mathrm{Na}-\mathrm{H}$ exchanger. These results demonstrate that preconditioning alters the kinetics of $\mathrm{Na}_{\mathbf{i}}$ accumulation during global ischemia as well as proton transport after $\mathrm{NH}_{4} \mathrm{Cl}$ washout. These observations are consistent with stimulation of the Na-K2Cl cotransporter and $\mathrm{Na}-\mathrm{H}$ exchanger by preconditioning.
\end{abstract}

Address correspondence to Division of Cardiovascular Medicine, TB 172, University of California, Davis, CA 95616. Phone: 916-752-0717; FAX: 916-752-3264.

Received for publication 26 October 1994 and accepted in revised form 16 May 1995.

J. Clin. Invest.

(C) The American Society for Clinical Investigation, Inc. 0021-9738/95/09/1464/09\$2.00

Volume 96, September 1995, 1464-1472
(J. Clin. Invest. 1995. 96:1464-1472.) Key words: preconditioning $\bullet$ ischemia $\cdot$ magnetic resonance spectroscopy $\bullet$ Na$\mathrm{H}$ exchanger $\cdot \mathrm{Na}-\mathrm{K}-2 \mathrm{Cl}$ cotransporter

\section{Introduction}

Preconditioning is a phenomenon in which one or more brief periods of ischemia protect the myocardium during a subsequent period of ischemia, with the degree of protection classically defined as limitation of infarct size (1-3). Preconditioning has been demonstrated in a variety of species, but there are no clearly defined and accepted mechanisms to explain the endogenous cardioprotection of preconditioning. Several theories have been proposed to explain the possible mechanism(s) by which ischemic preconditioning reduces infarct size, including preservation of myocardial high energy stores during ischemia (4), adenosine receptor stimulation (5), activation of ATP-sensitive $\mathrm{K}^{+}$channels (6), and translocation and activation of protein kinase $C(7,8)$.

Ischemic preconditioning has been shown, by this group as well as by others, to limit acidosis during global ischemia (4, $9)$. Limitation of acidosis could be due to either $(a)$ reduced proton production or $(b)$ enhanced proton efflux. Reduced proton production would reduce the stimulus for increasing sodium entry via the $\mathrm{Na}-\mathrm{H}$ exchanger and potentially result in lower levels of intracellular sodium $\left(\mathrm{Na}_{\mathrm{i}}\right)$ during ischemia. Enhanced proton efflux, which may occur because of stimulation of the $\mathrm{Na}-\mathrm{H}$ exchanger, could, conversely, result in an increase in $\mathrm{Na}_{\mathrm{i}}$ during ischemia. Stimulation of the $\mathrm{Na}-\mathrm{H}$ exchanger by preconditioning would also alter the response of the heart to acidification resulting from an acid load in the absence of ischemia.

This study tested the hypothesis that ischemic preconditioning stimulates sodium-dependent proton efflux pathways ( such as the $\mathrm{Na}-\mathrm{H}$ exchanger) in the heart, resulting in increased proton efflux and reduced acidosis during subsequent ischemia. This hypothesis was tested using ${ }^{23} \mathrm{Na}$ and ${ }^{31} \mathrm{P}$ nuclear magnetic resonance (NMR) ${ }^{1}$ spectroscopy in preconditioned and control hearts to measure $(a)$ the response of intracellular $\mathrm{Na}^{+}$in perfused rat hearts during $30 \mathrm{~min}$ of global ischemia, $(b)$ the effect on intracellular $\mathrm{Na}^{+}$of inhibiting the $\mathrm{Na}-\mathrm{H}$ exchanger and Na$\mathrm{K}-2 \mathrm{Cl}$ cotransporter in preconditioned hearts, and $(c)$ the kinetics of proton extrusion in the absence of ischemia.

1. Abbreviations used in this paper: CK, creatine kinase; EIPA, ethylisopropylamiloride; gdw, grams dry weight; LVDP, left ventricular developed pressure; NMR, nuclear magnetic resonance; ppm, parts per million. 


\section{Methods}

\section{General methods}

All experiments were performed with the approval of the University of California, Davis, Animal Research Committee.

\section{Isolated heart model}

Experiments were performed using an isovolumic isolated perfused rat heart preparation. Male Sprague-Dawley rats $(\sim 350 \mathrm{~g})$ were pretreated with heparin (1,000 U intraperitoneally [IP]), followed by sodium pentobarbital $(65 \mathrm{mg} / \mathrm{kg}$ IP). After deep anesthesia was achieved as determined by the absence of a foot reflex, the heart was rapidly excised and placed into iced saline. The arrested heart was perfused in a retrograde manner through the aorta within $2 \mathrm{~min}$. The left ventricular developed pressure (LVDP) was determined using a latex balloon in the left ventricle, with high pressure tubing connected to a pressure transducer. Perfusion pressure (PP) was also monitored using high pressure tubing off the perfusion line. Hemodynamic measurements were recorded on a four-channel recorder (Windowgraf; Gould Inc., Valley View, $\mathrm{OH}$ ). The heart was perfused using an accurate roller pump at a flow rate of $12.5 \mathrm{ml} / \mathrm{min}$ (Rainin Instrument Co., Woburn, MA). The perfusate consisted of (in millimoles per liter) $\mathrm{NaCl}, 118 ; \mathrm{KCl}, 4 ; \mathrm{CaCl}_{2}, 1.2$; $\mathrm{MgCl}_{2}, 1 ; \mathrm{NaHCO}_{3}, 25$; with the substrate being $11 \mathrm{mM}$ glucose. The perfusion apparatus was tightly temperature controlled, with heated baths used for the perfusate and for the water jacketing around the perfusion tubing to maintain heart temperature at $37 \pm 0.5^{\circ} \mathrm{C}$ under al conditions. Oxygenation of the perfusate was provided by a pediatric hollow fiber oxygenator (Capiax II; Terumo Corp., Tokyo, Japan) immediately proximal to the heart. This preparation has routinely been stable for 3-4 h (10).

\section{Creatine kinase}

Creatine kinase (CK) was measured from timed 5-min collections of the effluent for $60 \mathrm{~min}$ of reperfusion after the ischemic period. This extended period of collection was employed because preliminary experiments showed that, in control hearts, CK release was maximal after $\sim 30 \mathrm{~min}$ of reperfusion and was stabilized within $60 \mathrm{~min}$. Each 5-min collection was analyzed in duplicate using established spectrophotometric methods (11). Total integrated CK activity over the reperfusion period was calculated for each heart and corrected for dry weight of the heart. CK release was expressed in IU/g dry weight (gdw). As previously shown (12), the integral of the $\mathrm{CK}$ release is a representative measure of ischemic injury and infarction.

\section{NMR spectroscopy}

Phosphorus-31. All NMR spectroscopy was performed on a vertical bore spectrometer (AMX 400; Bruker Instruments Inc., Billerica MA) using a switchable $20-\mathrm{mm}$ probe tuned for ${ }^{31} \mathrm{P}$ or ${ }^{23} \mathrm{Na}$. ${ }^{31} \mathrm{P}$ NMR spectroscopy was performed using 228 acquisitions of a $60^{\circ}$ pulse and a 1.6-s interpulse delay, with spectra processed using an exponential multiplication of $20 \mathrm{~Hz}$ and Fourier transformed. Intracellular $\mathrm{pH}$ was calculated from the chemical shift between the inorganic phosphate $\left(\mathrm{P}_{\mathrm{i}}\right)$ and phosphocreatine $(\mathrm{PCr})$ resonance using a titration curve established in this facility (13).

Sodium-23. Intracellular sodium content, $\mathrm{Na}_{\mathrm{i}}$, was determined using the shift reagent ( $7 \mathrm{mM}$ Dy (TTHA) $)^{3-}$ ) added to the standard perfusate throughout the entire experimental period. ${ }^{23} \mathrm{Na}$ spectra were acquired using the broad-band probe tuned to $105.85 \mathrm{MHz} .1,000$ free induction decays were signal averaged over $5 \mathrm{~min}$ using $90^{\circ}$ pulses with a $\pm 4,000$ $\mathrm{Hz}$ sweep width. ${ }^{23} \mathrm{Na}$ spectra were processed on the Bruker spectrometer. After baseline correction, the extracellular resonance was inverted, shifted, and subtracted from the original spectrum to obtain the intracellular resonance. The area of the intracellular resonance was determined without constraining the line fit to either a Lorentzian or Gaussian shape. These operations were performed in duplicate for each spectrum and the values averaged. The data acquired were normalized to an assumed

\section{Response to $\mathrm{NH}_{4} \mathrm{Cl}$ pre-pulse}

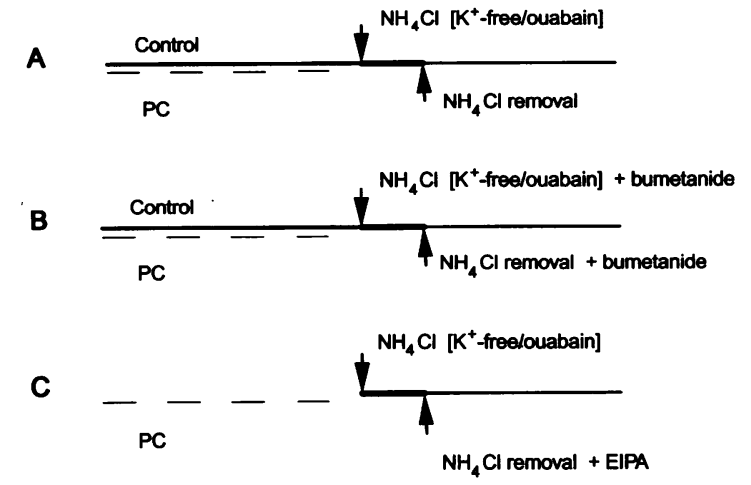

Figure 1. Protocol III. Schematic of the protocols measuring the $\mathrm{pH}$ response to an acid load $\left(\mathrm{NH}_{4} \mathrm{Cl}\right.$ exposure for $10 \mathrm{~min}$ and washout) in preconditioned and control hearts under the following conditions: $(A)$ $\mathrm{K}^{+}$-free perfusate with ouabain, $(B) \mathrm{K}^{+}$-free perfusate with ouabain and bumetanide $(10 \mu \mathrm{M})$ at the time of $\mathrm{NH}_{4} \mathrm{Cl}$ exposure and removal, and $(C)$ preconditioned hearts in which EIPA $(10 \mu \mathrm{M})$ was administered during $\mathrm{NH}_{4} \mathrm{CL}$ removal. Four hearts were studied in each group. Preconditioning consisted of four 5-min periods of total global ischemia with 5-min reperfusion periods (total $40 \mathrm{~min}$ ). Control perfusion consisted of $40 \mathrm{~min}$ of perfusion at normal flow.

baseline value of 10 at $-45 \mathrm{~min}$ and are expressed as normalized area units. To rule out any change in relaxation times during the protocol, half-height linewidths of the intracellular sodium resonance were calculated at three time points during the protocols. The chemical shifts between the extracellular and intracellular resonances were determined before, during, and after ischemia.

\section{Statistical methods}

Data were analyzed using INSTAT (GraphPad, San Diego, CA) software operating on an IBM-compatible personal computer. Differences at different time points within groups were assessed using ANOVA for repeated measures, with a subsequent Dunnett multiple comparisons test if the $P$ value for ANOVA was significant. Differences between groups at a given time point were assessed using the Mann-Whitney nonparametric test. Reproducibility of the intracellular sodium measurements was evaluated using linear regression of duplicate measurements. A $P$ value of less than 0.05 was used to reject the null hypothesis. All data are expressed as the mean \pm SEM.

\section{Protocols}

The protocols consisted of ischemia protocols (I and II) employing measurement of $\mathrm{Na}_{i}$, cardiac function, and $\mathrm{CK}$ release and a nonischemia protocol (III) in which the changes in $\mathrm{pH}$ in response to an acid load were measured. Protocol I measured functional recovery, creatine kinase release, and intracellular sodium kinetics in control hearts and preconditioned hearts. Protocol II measured functional recovery, CK release, and intracellular sodium kinetics in preconditioned hearts in which either ethylisopropylamiloride (EIPA, $3 \mu \mathrm{M}$, an inhibitor of the $\mathrm{Na}-\mathrm{H}$ exchanger) or bumetanide ( $5 \mu \mathrm{M}$, an inhibitor of the $\mathrm{Na}-\mathrm{K}-2 \mathrm{Cl}$ cotransporter) was added to the perfusate during the last reperfusion period before $30 \mathrm{~min}$ of global ischemia. These hearts were reperfused after 30 min with standard perfusate containing neither EIPA nor bumetanide. Protocol III (shown in Fig. 1 and described in detail below) measured the response to an acid load under three conditions: $(A) \mathrm{NH}_{4} \mathrm{Cl}$ prepulse; $(B) \mathrm{NH}_{4} \mathrm{Cl}$ prepulse with inhibition of the Na-K-2Cl cotransporter with bumetanide; and $(C) \mathrm{NH}_{4} \mathrm{Cl}$ prepulse with inhibition of the $\mathrm{Na}-\mathrm{H}$ exchanger during $\mathrm{pH}$ recovery. 


\section{Functional recovery and $C K$ release}

To determine whether use of the shift reagent had any effects on functional recovery or infarct size, hearts with and without ischemic preconditioning were studied both with and without DyTTHA ${ }^{3-}$ in the perfusate $\left(n=6\right.$ in each group). DyTTHA ${ }^{3-}$ was added to the perfusate after an initial stabilization period. After $40 \mathrm{~min}$ of perfusion, control hearts were subject to $30 \mathrm{~min}$ of global ischemia followed by $60 \mathrm{~min}$ of reperfusion. Preconditioned hearts were subject to four 5-min periods of no-flow ischemia, with each period of ischemia followed by $5 \mathrm{~min}$ of reperfusion. As in the control hearts, the preconditioned hearts were then subject to $30 \mathrm{~min}$ of global ischemia followed by $60 \mathrm{~min}$ of reperfusion.

\section{Response of intracellular sodium to ischemia and reperfusion}

Control $(n=8)$ and preconditioned (PC, $n=6)$ hearts were studied using ${ }^{23} \mathrm{Na}$ NMR. As in the functional measurements, hearts in each group were subjected to $30 \mathrm{~min}$ of global ischemia followed by $60 \mathrm{~min}$ of reperfusion after $40 \mathrm{~min}$ of either control perfusion or four 5-min preconditioning episodes all in the presence of DyTTHA ${ }^{3-}$. Preconditioned hearts in which EIPA $(n=5)$ or bumetanide $(n=5)$ was added to the hearts during the last reperfusion period before global ischemia were also studied using ${ }^{23} \mathrm{Na}$ NMR.

\section{Response to an acid load}

To test the hypothesis that preconditioning increases proton efflux, $\mathrm{pH}$ recovery was measured in 20 control and preconditioned hearts $(n=4$ in each condition) after exposure to an acid load in the three protocols described earlier. In each protocol, hearts were exposed to $20 \mathrm{mM}$ $\mathrm{NH}_{4} \mathrm{Cl}$ for $10 \mathrm{~min}$ in a $\mathrm{K}^{+}$-free buffer that contained $100 \mu \mathrm{M}$ ouabain to inhibit $\mathrm{Na}$ transport via $\mathrm{Na}, \mathrm{K}-\mathrm{ATPase}$. After this 10 -min exposure to $\mathrm{NH}_{4} \mathrm{Cl}$, hearts were perfused for 30 min with $\mathrm{K}^{+}$-free/ouabain buffer not containing $\mathrm{NH}_{4} \mathrm{Cl}$. This washout phase decreased $\mathrm{pH}$ as the $\mathrm{NH}_{4}{ }^{+}$ that had previously entered then dissociated into $\mathrm{NH}_{3}+\mathrm{H}^{+}(14)$. The ability of the cell to extrude protons was then reflected in the subsequent increase in $\mathrm{pH}$. The first protocol $(A)$ did not contain any membrane transport inhibitors during the $\mathrm{NH}_{4} \mathrm{Cl}$ exposure or washout other than the $\mathrm{K}^{+}$-free/ouabain buffer. Because preconditioning could affect the $\mathrm{Na}-\mathrm{K}-2 \mathrm{Cl}$ cotransporter, which is a potential mechanism for $\mathrm{NH}_{4}$ transport into the cell (15), the second protocol $(B)$ included $10 \mu \mathrm{M}$ bumetanide during $\mathrm{NH}_{4} \mathrm{Cl}$ exposure and removal to inhibit the Na-K-2C1 cotransporter. The third protocol $(C)$ employed $10 \mu \mathrm{M}$ EIPA during the $\mathrm{NH}_{4} \mathrm{Cl}$ washout phase to determine the role of the $\mathrm{Na}-\mathrm{H}$ exchanger in preconditioned hearts.

\section{Results}

\section{Function}

Use of the shift reagent Dy (TTHA) ${ }^{3-}$ during ${ }^{23} \mathrm{Na}$ NMR experiments did not alter cardiac function in either the control or preconditioned hearts. LVDP was not different in any group under baseline conditions before global ischemia $(84 \pm 8 \mathrm{mmHg}$ in the control hearts, $76 \pm 7 \mathrm{mmHg}$ in the control hearts with $7 \mathrm{mM}$ Dy(TTHA) ${ }^{3-}, 82 \pm 8 \mathrm{mmHg}$ in the preconditioned hearts, $79 \pm 7 \mathrm{mmHg}$ in the preconditioned hearts with $7 \mathrm{mM}$ Dy(TTHA $)^{3-}$ ) and fell to 0 during the first $5 \mathrm{~min}$ of global ischemia in all hearts. Similarly, heart rates were identical in all the groups during baseline conditions, and ischemia caused a rapid cessation of cardiac rhythm. Reperfusion of the control hearts resulted in limited functional recovery. LVDP and rhythmic activity did not recover in three hearts, with the average developed pressure only $12 \pm 5 \mathrm{mmHg}$ after $60 \mathrm{~min}$ of reperfusion in the remaining hearts $(P<0.01$ vs. PC). All the preconditioned hearts exhibited significant functional recovery, with
LVDP recovering to $48 \pm 7 \mathrm{mmHg}$ after $60 \mathrm{~min}$ of reperfusion. This degree of functional recovery was similar to that observed in our earlier studies (9).

Preconditioned hearts treated with EIPA in the last reperfusion period before ischemia had significant diminution of functional recovery compared with preconditioned hearts. Left ventricular developed pressure was $79 \pm 8 \mathrm{mmHg}$ before ischemia and $27 \pm 7 \mathrm{mmHg}(P<0.05$ vs. PC) at the end of reperfusion. Similarly, treatment with bumetanide reduced developed pressure from $78 \pm 6 \mathrm{mmHg}$ before ischemia to $16 \pm 6 \mathrm{mmHg}$ ( $P$ $<0.01)$ at the end of reperfusion.

\section{Ischemic injury}

CK release, a measure of myocardial injury and infarction, was significantly reduced after $30 \mathrm{~min}$ of global ischemia in the preconditioned hearts and was not affected by DyTTHA (CK release: $1186 \pm 117 \mathrm{IU} / \mathrm{gdw}$ in control hearts, $372 \pm 63$ in the preconditioned hearts, and $414 \pm 54$ in the preconditioned hearts with $7 \mathrm{mM}$ Dy (TTHA) $)^{3-}$ ); $P<0.01$ preconditioned vs control hearts). These reductions in ischemic injury following preconditioning are similar to those observed in our earlier studies (9). Treatment with EIPA or bumetanide before ischemia resulted in CK release that was similar to that in control hearts and significantly greater than that in preconditioned hearts (EIPA, $1257 \pm 244 \mathrm{IU} / \mathrm{gdw}$; bumetanide, $1522 \pm 236 \mathrm{IU} / \mathrm{gdw} ; P<0.05$ vs preconditioned hearts).

\section{Intracellular $\left[\mathrm{Na}^{+}\right]$in preconditioned hearts}

Fig. 2 displays the ${ }^{23} \mathrm{Na}$ NMR spectra of intracellular and extracellular sodium in preconditioned and control hearts, while Fig. 3 illustrates the changes in $\mathrm{Na}_{\mathrm{i}}$ in control and preconditioned hearts. The intracellular resonance appeared as a shoulder on the large extracellular resonance under baseline conditions, but became more conspicuous during the $30-\mathrm{min}$ global ischemia period. Because accurate and reproducible measurement of the intracellular sodium resonance was critical in these experiments, we examined $(a)$ the changes in $\mathrm{T} 2$ relaxation times and, hence, linewidths of the intracellular sodium resonance during the experiments, $(b)$ the chemical shifts between the intra- and extracellular resonances before, during, and after ischemia; and (c) the reproducibility of the two separate analyses of the intracellular sodium resonance areas. The half-height linewidths did not change during the experiments. The linewidths in the preconditioned hearts were baseline $(-45 \mathrm{~min}), 83 \pm 3 \mathrm{~Hz}$; immediately before global ischemia $(0 \mathrm{~min}), 84 \pm 4 \mathrm{~Hz}$; and at the end of global ischemia (30 min), $86 \pm 4 \mathrm{~Hz}$. Similarly, the linewidths in the control hearts were baseline $(-45 \mathrm{~min}), 86 \pm 4 \mathrm{~Hz}$; immediately before global ischemia $(0 \mathrm{~min}), 86 \pm 4 \mathrm{~Hz}$; and at the end of global ischemia $(30 \mathrm{~min}), 84 \pm 4 \mathrm{~Hz}$. The changes in chemical shift differences from immediately before global ischemia $(0 \mathrm{~min})$ to the end of global ischemia $(30 \mathrm{~min})$ were not different between the groups (control, $0.07 \pm 0.05$; PC, $0.01 \pm 0.03 \mathrm{ppm}$ ); similarly the changes in chemical shift differences from the end of global ischemia and $5 \mathrm{~min}$ after reperfusion were not different (control, $0.01 \pm 0.002 \mathrm{ppm}$; PC, $0.07 \pm 0.03 \mathrm{ppm}$ ). The correlation coefficient for separate analyses of the raw intracellular sodium resonance areas was 0.95 .

As observed in Fig. 3, the four preconditioning episodes progressively increased $\mathrm{Na}_{\mathrm{i}}$ from its baseline value. Although the increases in $\mathrm{Na}_{\mathrm{i}}$ from the baseline value were not significant by ANOVA, these changes resulted in $\mathrm{Na}_{\mathrm{i}}$ that was greater in 
A
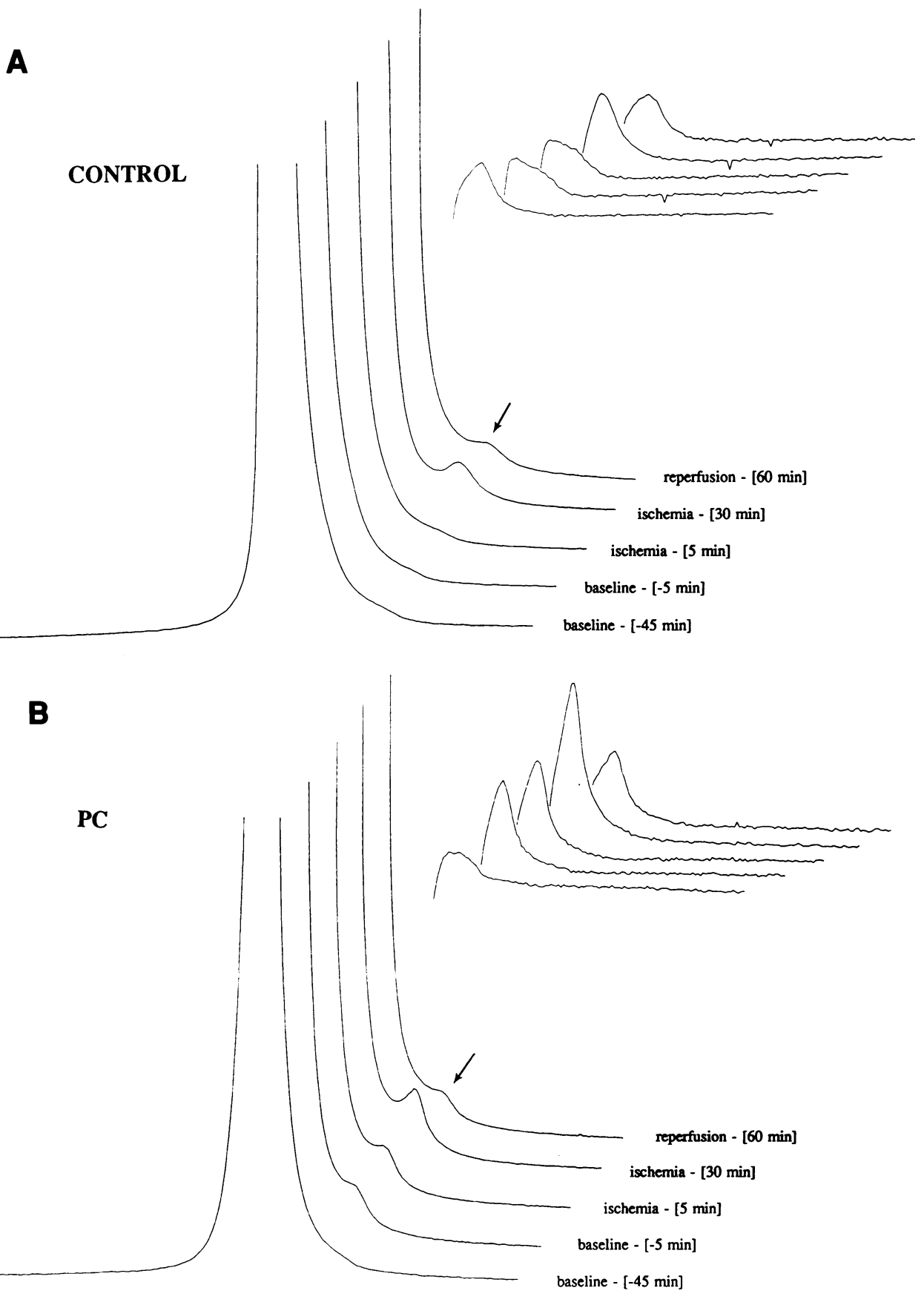

Figure 2. Representative ${ }^{23} \mathrm{Na}$ NMR spectra of isolated rat hearts perfused with $7 \mathrm{mM}$ Dy (TTHA) $)^{3-}$ in modified oxygenated Krebs-Hensleit buffer obtained from $(A)$ control or $(B)$ preconditioned (PC) hearts at the time points shown. The spectra demonstrate the large extracellular sodium resonance (shifted downfield by the shift reagent) and the small intracellular sodium resonances (arrow) under these conditions. Inset in each figure are the intracellular resonances derived by subtracting the extracellular resonances. Although the chemical shift of the resonances in these hearts is slightly different, it is apparent that the intracellular sodium resonance is increased by the preconditioning episodes (baseline, $-5 \mathrm{~min}$ ) and is further increased during ischemia. In contrast, the intracellular sodium resonance in the control hearts does not increase under baseline perfusion conditions.

the preconditioned than in the control hearts $5 \mathrm{~min}$ before the 30-min ischemia period $(P<0.05)$. As seen in Fig. 4 , there was a rapid and significant increase in $\mathrm{Na}_{\mathrm{i}}$ during the first 5 min of the ischemia period in the preconditioned hearts but not in the control hearts, with intracellular $\mathrm{Na}_{\mathrm{i}}$ increasing $8.48 \pm 1.21$ $\mathrm{U}$ in the preconditioned hearts compared with $2.57 \pm 0.81 \mathrm{U}$ in the control hearts $(P<0.01)$. The subsequent changes in $\mathrm{Na}_{\mathrm{i}}$ during ischemia were similar in the preconditioned and control hearts, yielding similar end-ischemia values before reperfusion. Intracellular sodium decreased by $13.48 \pm 1.73 \mathrm{U}$, or $30 \%$ of its final ischemia value, in the preconditioned hearts during the first 5 min of reperfusion, compared with a decrease of $2.54 \pm 1.24 \mathrm{U}$, or $6 \%$ of its final ischemia value, in the control hearts $(P$
$<0.001)$. Thus, the response of $\mathrm{Na}_{\mathrm{i}}$ during ischemia in the preconditioned hearts was characterized by an accelerated increase in $\mathrm{Na}_{i}$ at the onset of ischemia and accelerated decrease on reperfusion.

As in the untreated preconditioned hearts, the preconditioned hearts treated with either EIPA or bumetanide during the last reperfusion period before $30 \mathrm{~min}$ of global ischemia demonstrated gradual increases in $\mathrm{Na}_{\mathrm{i}}$ during the preconditioning episodes ( $8.48 \pm 0.48$ and $11.94 \pm .9 .92 \mathrm{U}$, respectively; Fig. 5), resulting in values of $\mathrm{Na}_{\mathrm{i}}$ that were significantly higher than those of the control hearts before global ischemia ( $P$ $<0.05)$. The increase in $\mathrm{Na}_{\mathrm{i}}$ during $30 \mathrm{~min}$ of global ischemia in the EIPA-treated hearts $(7.50 \pm 0.94 \mathrm{U})$ was significantly re- 


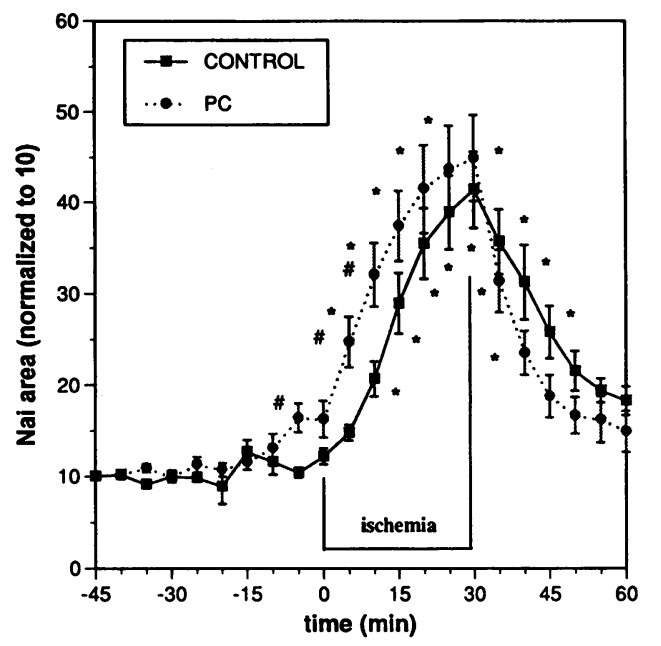

Figure 3. Changes in intracellular sodium resonance area $\left(\mathrm{Na}_{\mathrm{i}}\right)$ as a function of time in control and preconditioned (PC) hearts, with the initial intracellular resonance at $-45 \mathrm{~min}$ in each heart normalized to 10. ${ }^{*} P<0.05$ vs. control hearts; ${ }^{*} P<0.05$ vs. baseline measurement for each group.

duced compared with that in either control or preconditioned hearts, while the increase in $\mathrm{Na}_{\mathrm{i}}$ was not reduced by bumetanide $(17.56 \pm 1.53 \mathrm{U})$. The end-ischemia value of $\mathrm{Na}_{\mathrm{i}}$ in the bumetanide-treated hearts was significantly higher than that in the EIPA-treated hearts $(P<0.05)$. The decrease in $\mathrm{Na}_{\mathrm{i}}$ during the first $5 \mathrm{~min}$ of reperfusion in the EIPA- and bumetanidetreated hearts was similar to that of control hearts and significantly less than that of preconditioned hearts. All groups had similar values of $\mathrm{Na}_{\mathrm{i}}$ at the end of reperfusion.

\section{Response to an acid load $\left(\mathrm{NH}_{4} \mathrm{Cl}\right.$ prepulse)}

The response of control and preconditioned hearts to an acid load is shown in Fig. 6. Each 5-min preconditioning episode

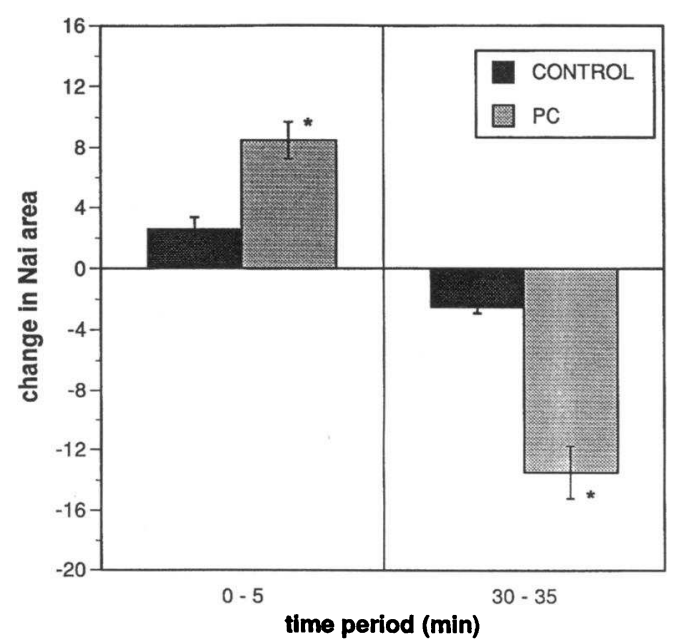

Figure 4. Changes in normalized intracellular sodium $\left(\mathrm{Na}_{\mathrm{i}}\right)$ resonance area during the onset of ischemia $(0-5 \mathrm{~min})$ and the onset of reperfusion (30-35 $\mathrm{min}$ ) in control and preconditioned (PC) hearts. Areas derived from data shown in Fig. 3. The preconditioned hearts had significantly greater changes in $\mathrm{Na}_{\mathrm{i}}$ than did the control hearts during these time periods. ${ }^{*} P<0.05$ preconditioned vs. control hearts.

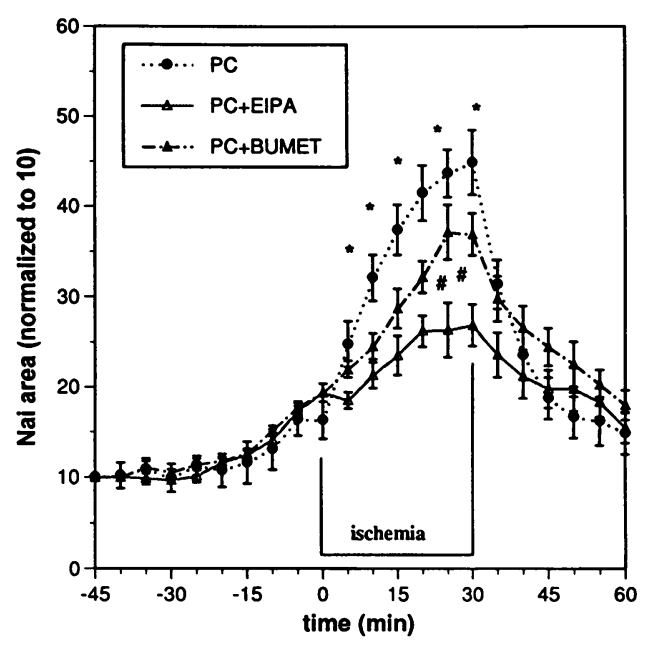

Figure 5. Changes in intracellular sodium $\left(\mathrm{Na}_{\mathrm{i}}\right)$ resonance area as a function of time in preconditioned hearts exposed to either ethylisoproplyamiloride $(P C+E I P A, \triangle)$ or bumetanide $(P C+B U M E T, \triangle)$ during the last reperfusion period prior to global ischemia. The data from the preconditioned hearts $(P C, \bullet)$ are from Fig. 3. $* P<0.05$ PC hearts vs. PC + EIPA; ${ }^{*} P<0.05$ PC + BUMET vs. PC + EIPA

significantly reduced intracellular $\mathrm{pH}$ (range, 6.38 \pm 0.02 [ first ischemia period] to $6.46 \pm 0.01$ [last ischemia period]), with recovery to normal $\mathrm{pH}$ with each reperfusion episode (data not

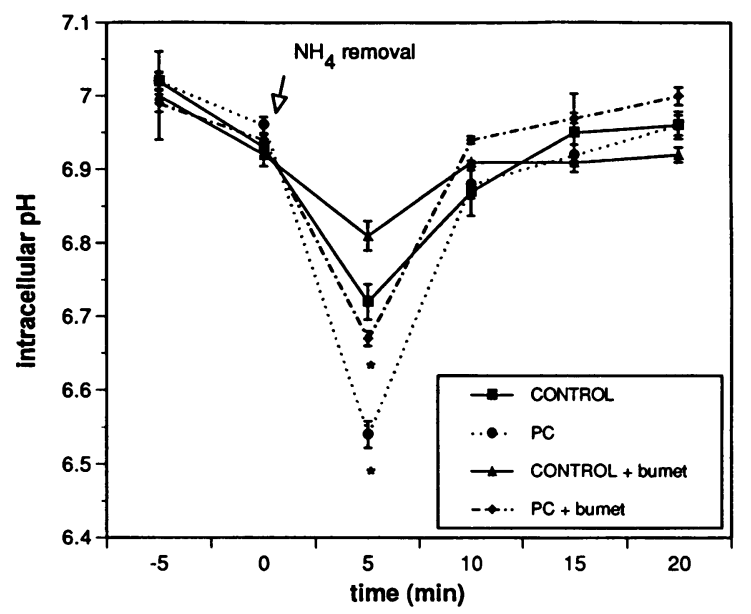

Figure 6. Changes in intracellular $\mathrm{pH}$ as a function of time in control and preconditioned hearts without (control, 1 and preconditioned $(P C)$, $\bullet)$ and with (control, $\Delta$ and preconditioned, $\bullet$ ) bumetanide added to the perfusate during $\mathrm{NH}_{4} \mathrm{Cl}$ exposure and washout. The hearts were exposed to $\mathrm{NH}_{4} \mathrm{Cl}$ for $10 \mathrm{~min}$ followed by washout in $\mathrm{K}^{+}$-free buffer containing ouabain as described in Fig. 1. The data points during $\mathrm{NH}_{4} \mathrm{Cl}$ exposure (time -5 and $0 \mathrm{~min}$ ) and during $\mathrm{NH}_{4} \mathrm{Cl}$ washout (time 5-20 min) are shown here. $\mathrm{NH}_{4} \mathrm{Cl}$ was removed from the perfusate at the end of the acquisition period marked " $\mathrm{NH}_{4}$ removal." Bumetanide eliminated the greater acidification of the preconditioned hearts, suggesting that greater acidification was due to increased activity of the $\mathrm{Na}-\mathrm{K}-2 \mathrm{Cl}$ cotransporter. Rapid $\mathrm{pH}$ recovery was maintained in the preconditioned hearts despite the presence of bumetanide and a nadir $\mathrm{pH}$ equal to that of control hearts, suggesting that this recovery was independent of the cotransporter. ${ }^{*} P<0.05 \mathrm{PC}$ and $\mathrm{PC}+$ bumetanide vs. control and control + bumetanide hearts, respectively. 


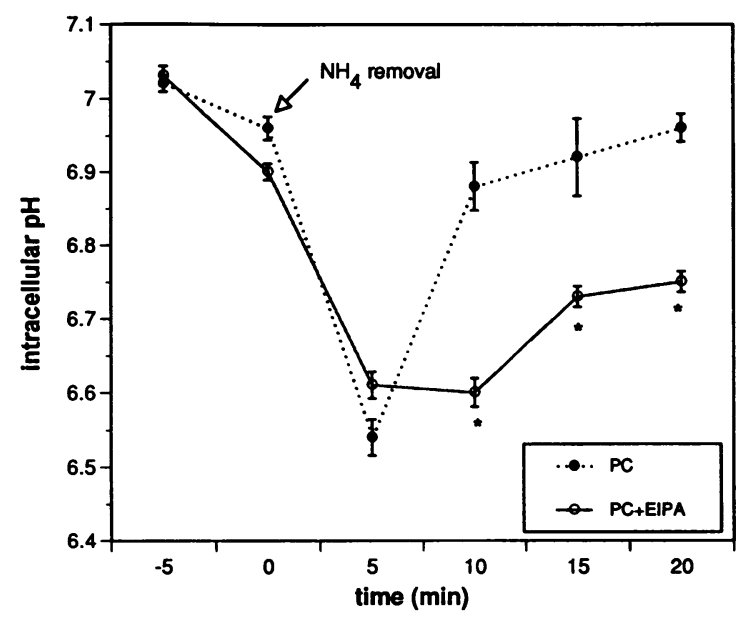

Figure 7. Changes in $\mathrm{pH}$ in preconditioned hearts (PC) during and after $\mathrm{NH}_{4} \mathrm{Cl}$ exposure, with addition of EIPA at the time of $\mathrm{NH}_{4} \mathrm{Cl}$ removal (O). Conditions were identical to experiments shown in Fig. 6. Data in the preconditioned hearts without EIPA $(\bullet)$ are from Fig. $6 .{ }^{*} P<0.05$ vs. preconditioned hearts without EIPA.

shown). The $\mathrm{pH}$ during the exposure to $\mathrm{NH}_{4} \mathrm{Cl}$ was identical between the preconditioned and control hearts groups $(7.02 \pm 0.02$ after $10 \mathrm{~min})$. Preconditioned hearts exhibited greater acidification and a more rapid recovery of $\mathrm{pH}$ after exposure and removal of $\mathrm{NH}_{4} \mathrm{Cl}$. The nadir $\mathrm{pH}$ was observed in the spectrum acquired $5 \mathrm{~min}$ after removal of $\mathrm{NH}_{4} \mathrm{Cl}$ and equalled $6.72 \pm 0.02$ in the control hearts compared with $6.54 \pm 0.02$ in the preconditioned hearts $(P<0.05)$. The preconditioned hearts had a rapid $\mathrm{pH}$ recovery during the washout phase $(\Delta \mathrm{pH}=0.35 \pm 0.04$ over $5 \mathrm{~min})$, while the control hearts had a significantly slower $\mathrm{pH}$ recovery $(\Delta \mathrm{pH}=0.15 \pm 0.02)$. Both groups of hearts achieved the same final $\mathrm{pH}$ at the end of the measurement period $(6.96 \pm 0.02)$.

Response to an acid load $\left(\mathrm{NH}_{4} \mathrm{Cl}\right.$ prepulse) with inhibition of the $\mathrm{Na}-\mathrm{K}-2 \mathrm{Cl}$ cotransporter. Because the increased acidification observed in the preconditioned hearts could be a result of increased entry of $\mathrm{NH}_{4}{ }^{+}$via the $\mathrm{Na}-\mathrm{K}-2 \mathrm{Cl}$ cotransporter $\left(\mathrm{NH}_{4}{ }^{+}\right.$ can substitute for $\mathrm{K}^{+}$on the cotransporter) (15), further experiments were performed in the presence of $10 \mu \mathrm{M}$ bumetanide (a potent inhibitor of the $\mathrm{Na}^{+}-\mathrm{K}^{+}-2 \mathrm{Cl}^{-}$cotransporter) (16, 17). The results, shown in Fig. 6, demonstrate that bumetanide significantly limited intracellular acidification in both the preconditioned and control hearts although, as in the prior experiments, the preconditioned hearts acidified more than the control hearts and alkalinized more rapidly $(\Delta \mathrm{pH}=0.28 \pm 0.02$ vs. $\Delta \mathrm{pH}=0.10 \pm 0.03$ over $5 \mathrm{~min}$, preconditioned vs. control, respectively; $P<0.001)$. The lower nadir $\mathrm{pH}$ in the preconditioned hearts in the absence of bumetanide suggests greater $\mathrm{NH}_{4}{ }^{+}$entry into the heart via the $\mathrm{Na}-\mathrm{K}-2 \mathrm{Cl}$ cotransporter, and therefore that preconditioning stimulated inward flux of the cotransporter.

Despite these differences in nadir $\mathrm{pH}$ in the presence or absence of bumetanide, the rate of $\mathrm{pH}$ recovery after an ammonium prepulse in the preconditioned hearts was similar in the presence and absence of bumetanide $(\Delta \mathrm{pH}=0.28 \pm 0.02$ in the presence of bumetanide, $\Delta \mathrm{pH}=0.35 \pm 0.04$ in the absence of bumetanide over $5 \mathrm{~min}$; Fig. 6 ), suggesting that the enhanced
$\mathrm{pH}$ recovery of the preconditioned hearts after an acid load did not involve the $\mathrm{Na}-\mathrm{K}-2 \mathrm{Cl}$ cotransporter.

Response to an acid load $\left(\mathrm{NH}_{4} \mathrm{Cl}\right.$ prepulse) with inhibition of the $\mathrm{Na}^{+}-\mathrm{H}^{+}$exchanger. To determine the role of the $\mathrm{NaH}$ exchanger in $\mathrm{pH}$ recovery after an acid load, experiments similar to those above were performed in which the $\mathrm{Na}-\mathrm{H}$ exchanger was inhibited by $10 \mu \mathrm{M}$ EIPA during the washout phase after an ammonium prepulse (18). Fig. 7 demonstrates that the presence of EIPA retarded $\mathrm{pH}$ recovery in preconditioned hearts. The preconditioned hearts without EIPA had a rapid recovery to normal $\mathrm{pH}$ during the washout phase $(\Delta \mathrm{pH}=0.35 \pm 0.04$ in the first $15 \mathrm{~min}$ ), while preconditioned hearts with EIPA had no $\mathrm{pH}$ recovery for the first $5 \mathrm{~min}$, and subsequently had limited $\mathrm{pH}$ recovery. This response resulted in significantly lower $\mathrm{pH}$ values than in the absence of EIPA. Comparison of these differences in $\mathrm{pH}$ recovery with and without EIPA suggests that all of the $\mathrm{pH}$ recovery in the first 5-min period after the $\mathrm{pH}$ nadir in the preconditioned hearts occurred via the $\mathrm{Na}-\mathrm{H}$ exchanger.

\section{Discussion}

This study has demonstrated that ischemic preconditioning resulted in a rapid increase in $\mathrm{Na}_{\mathrm{i}}$ at the onset of global ischemia and a rapid decrease on reperfusion, consistent with stimulation of mechanisms that enhance sodium transport across the sarcolemma under these conditions. The response of preconditioned hearts to an acid load under conditions in which the Na-KATPase and $\mathrm{Na}-\mathrm{K}-2 \mathrm{Cl}$ cotransporter were inhibited are consistent with preconditioning stimulating the $\mathrm{Na}-\mathrm{K}-2 \mathrm{Cl}$ cotransporter (resulting in increased acidosis following a $\mathrm{NH}_{4} \mathrm{Cl}$ prepulse) and the $\mathrm{Na}-\mathrm{H}$ exchanger (resulting in more rapid recovery from acidosis). In support of a role for stimulation of these sodium transport mechanisms in the protective effect of preconditioning, inhibition of these changes in sodium transport blunted the protective effects of preconditioning on functional recovery and on ischemic injury.

$\mathrm{Na}^{+}{ }_{i}$ accumulation in preconditioning. Few studies have measured intracellular sodium during ischemia in preconditioned hearts $(19,20)$. In adult rat hearts, Steenbergen et al. (19) used the sodium shift reagent thulium-DOTP ${ }^{5-}$ in combination with the calcium chelator 5F-BAPTA in a protocol similar to the one employed in the current study. They found no significant differences in $\mathrm{Na}_{\mathrm{i}}$ between control and preconditioned hearts. The current observations of a rapid increase in $\mathrm{Na}_{\mathrm{i}}$ at the onset of ischemia, no reduction in $\mathrm{Na}_{\mathrm{i}}$ at the end of ischemia, and a rapid decrease in $\mathrm{Na}_{\mathrm{i}}$ on reperfusion were not seen by Steenbergen et al. (19). The failure to demonstrate these kinetic changes in $\mathrm{Na}^{+}{ }_{\mathrm{i}}$ in their study may have been due to $(a)$ loading of perfused hearts with the calcium chelator 5FBAPTA, resulting in low developed pressure throughout the experiment; (b) the presence of at least $20 \mathrm{mM} \mathrm{NH}_{4}$ as a counter-cation with their shift reagent (based on the preparation methodology employed); and (c) baseline ischemia preparations, signified by low pre-ischemia $\mathrm{PCr} / \mathrm{ATP}$ ratios and progressive reductions in $\mathrm{pH}$ with the preconditioning episodes before global ischemia.

$\mathrm{Na}$ transport mechanisms. The observed changes in $\mathrm{Na}_{\mathrm{i}}$, and particularly the rapid increase in $\mathrm{Na}_{\mathrm{i}}$ at the onset of ischemia in the preconditioned hearts, are consistent with stimulation of transport mechanisms that increase sodium entry into the cell. These mechanisms include the $\mathrm{Na}-\mathrm{K}-2 \mathrm{Cl}$ cotransporter and the 
$\mathrm{Na}^{+}-\mathrm{H}^{+}$exchanger, with stimulation of either potentially resulting in reduced intracellular acidosis during ischemia. Regulation of the $\mathrm{Na}-\mathrm{K}-2 \mathrm{Cl}$ cotransporter is multifactorial, with evidence that the cotransporter is regulated by changes in cell volume (15) and cyclic-AMP-dependent (21-23) and noncAMP-dependent protein phosphorylation (24) as well as ionic concentration gradients. Increased inward cotransporter flux during ischemia after preconditioning could be beneficial in protecting the heart through its functional coupling with the $\mathrm{Cl} /$ $\mathrm{HCO}_{3}$ exchanger (25). In this paradigm, chloride transported into the cell by the $\mathrm{Na}-\mathrm{K}-2 \mathrm{Cl}$ cotransporter may exit via $\mathrm{Cl} /$ $\mathrm{HCO}_{3}$ exchange, thus increasing intracellular $\mathrm{HCO}_{3}$ and limiting acidosis.

The primary factors regulating the $\mathrm{Na}-\mathrm{H}$ exchanger include the intracellular proton concentration and the phosphorylation state $(26,27)$. Under baseline conditions, the exchanger contributes to the extracellular/intracellular proton gradient with net outward transport of protons (28). Under conditions of ischemia in which protons are generated and intracellular $\mathrm{pH}$ decreases, the exchanger is stimulated to increase extrusion of protons, although with an obligatory increase in inward transport of sodium ions (29). The prior observations of reduced acidification during ischemia (9) and the current observations of an increased rate of intracellular sodium accumulation following preconditioning are consistent with stimulation of either the cotransporter or exchanger by preconditioning. These findings are similar to those observed by Bak and Ingwall (30) in hyperthyroid rat hearts in which increased activity of the $\mathrm{Na}-\mathrm{H}$ exchanger resulted in higher $\mathrm{pH}$ during global ischemia, and may also explain the excellent recovery of function in hypertrophied hearts from hyperthyroid rats after global ischemia (31).

Reduction in $\mathrm{Na}_{i}$ on reperfusion. Despite similar levels of intracellular sodium during ischemia in the preconditioned hearts, there was a significantly more rapid reduction in $\mathrm{Na}_{\mathrm{i}}$ on reperfusion, presumably reflecting increased sodium efflux. These findings are concordant with the rapid reduction in $\mathrm{Na}_{1}$ observed by Tani and Neely (32) in hearts pretreated by $10 \mathrm{~min}$ of anoxia before global ischemia (a likely "preconditioning" stimulus). Although previous studies have demonstrated that the cotransporter is directed into the cell under control conditions (33), arguments concerning thermodynamics and previous studies $(34,35)$ show that the cotransporter may be directed out of the cell during ischemia and reperfusion. Therefore, one potential mechanism that could increase sodium efflux under conditions of high intracellular sodium and chloride at the end of ischemia (36) is outward flux through the Na- $\mathrm{K}-2 \mathrm{Cl}$ cotransporter. A significant role for this mechanism is supported by the acidification of preconditioned hearts after exposure to $\mathrm{NH}_{4} \mathrm{Cl}$ (as discussed below) and the deleterious effect that bumetanide (a Na-K-2Cl cotransporter inhibitor) had on inhibiting sodium efflux during reperfusion when $\mathrm{Na}, \mathrm{K}$-ATPase was inhibited (35).

Response to an acid load in preconditioning: acidification. The $\mathrm{pH}$ response to an acid load using ammonium prepulse experiments is an established measure to differentiate the possible mechanisms involved in proton extrusion and, as used in this study, provides insight into the effect of preconditioning on the $\mathrm{Na}-\mathrm{K}-2 \mathrm{Cl}$ cotransporter and $\mathrm{Na}-\mathrm{H}$ exchanger. Under the conditions of the present experiments $\left(\mathrm{K}^{+}\right.$-free perfusate containing ouabain), acidification on $\mathrm{NH}_{4}{ }^{+}$removal was likely to be the result of entry of $\mathrm{NH}_{4}^{+}$by the $\mathrm{K}^{+}$channels or Na-K-
$2 \mathrm{Cl}$ cotransporter. Because the greater reduction in $\mathrm{pH}$ after removal of $\mathrm{NH}_{4} \mathrm{Cl}$ in the preconditioned hearts was eliminated by bumetanide, increased acidification in the preconditioned hearts was likely due to stimulation of the $\mathrm{Na}-\mathrm{K}-2 \mathrm{Cl}$ cotransporter. There are several mechanisms by which $\mathrm{Na}-\mathrm{K}-2 \mathrm{Cl}$ cotransporter activity could be altered. Opening of ATP-sensitive potassium channels ( $K_{A T P}$ channels $)$, known to be involved in several models of preconditioning (37), could increase extracellular $\mathrm{K}^{+}$and increase inward cotransporter flux (34). Alternatively, because protein kinase activation has been implicated in preconditioning (8), direct phosphorylation of the cotransporter could similarly increase inward flux.

Response to an acid load in preconditioning: $\mathrm{pH}$ recovery. The experiments measuring the effect of preconditioning after an acid load also support a significant effect of preconditioning on the activity of the Na-H exchanger. Potential mechanisms that "effectively" extrude protons from the myocyte include, in addition to the $\mathrm{Na}-\mathrm{H}$ exchanger, the $\mathrm{Cl}^{-}-\mathrm{HCO}_{3}{ }^{-}$exchanger and the $\mathrm{CO}_{2}$-lactate cotransporter, although involvement of the $\mathrm{Na}^{+}$-dependent $\mathrm{HCO}_{3}$ transporter is also possible (14). The more rapid rate of intracellular $\mathrm{pH}$ recovery from an acid load in the preconditioned hearts compared with control hearts demonstrates increased proton extrusion, while the substantial effect of EIPA in limiting $\mathrm{pH}$ recovery is clear evidence for a significant role of the $\mathrm{Na}-\mathrm{H}$ exchanger on $\mathrm{pH}$ recovery in preconditioned hearts. These data demonstrating an important role for the Na-H exchanger in the recovery of $\mathrm{pH}$ after an acid load are consistent with data from Lieberman (28), in which stimulation of the $\mathrm{Na}-\mathrm{H}$ exchanger enhanced $\mathrm{pH}$ recovery following an acid perturbation.

Potential mechanisms of $\mathrm{Na}-\mathrm{H}$ exchanger activation in preconditioning. Although these data show that kinetics of $\mathrm{Na}_{\mathrm{i}}$ accumulation are increased by preconditioning, the mechanism(s) of this increase can only be postulated. Recent data have shown that protein kinase $\mathrm{C}$ is activated and translocated during preconditioning, and that protein-kinase-C-dependent phosphorylation is necessary for the protective effects observed in preconditioned hearts $(7,8)$. It was shown in those studies that administering a protein kinase $\mathrm{C}$ inhibitor just before the sustained ischemia abolished the protective effect of preconditioning, while activation of protein kinase $\mathrm{C}$ by phorbol ester pretreatment mimicked preconditioning. Wallert and Frohlich (38) have also shown that the cardiac $\mathrm{Na}-\mathrm{H}$ exchanger is stimulated by activation of protein kinase C, as well as by $\alpha$-adrenergic stimulation, and that stimulation of the $\mathrm{Na}-\mathrm{H}$ exchanger restored intracellular $\mathrm{pH}$ to normal values within minutes after an acid load. These studies therefore suggest a mechanism by which the $\mathrm{Na}-\mathrm{H}$ exchanger is activated by preconditioning; namely, that activation and translocation of protein kinase $\mathrm{C}$ by preconditioning before ischemia stimulates the $\mathrm{Na}-\mathrm{H}$ exchanger, subsequently limiting acidification during ischemia.

In addition to activation of protein kinase $\mathrm{C}$, other mechanisms for enhanced activity of the $\mathrm{Na}-\mathrm{H}$ exchanger may be related to the repetitive, transient acidosis elicited by the preconditioning episodes. The intracellular acidification seen with each preconditioning episode ( $\mathrm{pH}$ approximately 6.45 ) is sufficient to transiently increase proton efflux via the $\mathrm{Na}-\mathrm{H}$ exchanger (29), and it is possible that repetitive stimulation of the exchanger could increase the number of active sites or copies of the exchanger in the cell membrane.

Inhibition of the $\mathrm{Na}-\mathrm{H}$ exchanger and/or $\mathrm{Na}-\mathrm{K}-2 \mathrm{Cl}$ cotrans- 
porter. The current experiments show that pharmacologic interventions that inhibit the $\mathrm{Na}-\mathrm{H}$ exchanger or $\mathrm{Na}-\mathrm{K}-2 \mathrm{Cl}$ cotransporter after preconditioning (but before global ischemia) blunt the protective effects of preconditioning on functional recovery and, in the case of EIPA, on ischemic injury. These results, while supporting the protective effect of stimulation of proton and sodium transport observed in preconditioned hearts, raise issues regarding the protective role of inhibition of either the Na$\mathrm{H}$ exchanger or $\mathrm{Na}-\mathrm{K}-2 \mathrm{Cl}$ cotransporter during ischemia. Because inhibition of the $\mathrm{Na}-\mathrm{H}$ exchanger or $\mathrm{Na}-\mathrm{K}-2 \mathrm{Cl}$ cotransporter before ischemia in the absence of preconditioning has been shown to limit the increase in $\mathrm{Na}_{\mathrm{i}}$ and be protective $(39,40)$, the lack of significant protection by EIPA or bumetanide in the current experiments suggests that there may be beneficial effects of sodium transport stimulation by preconditioning that are subsequently counteracted by the inhibitory effects of these agents.

Limitations. Whereas the current findings strongly support the hypothesis that ischemic preconditioning increases intracellular sodium concentration before ischemia and enhances proton efflux during ischemia, these observations must be interpreted within the limitations of the experimental design. First, the isolated heart model may not represent the in situ preconditioning effects observed in regional ischemia (1). However, the beneficial effects of preconditioning on myocardial function and ischemic injury parallel those in other models, as do the effects on high energy phosphates and $\mathrm{pH}$ (4). Thus, these similarities suggest that this model is representative of preconditioning. Second, while we have primarily addressed alterations in the $\mathrm{Na}-\mathrm{H}$ exchanger and $\mathrm{Na}-\mathrm{K}-2 \mathrm{Cl}$ cotransporter, other mechanisms limiting proton production $(9,41)$ or enhancing effective proton efflux (such as the $\mathrm{Cl} / \mathrm{HCO}_{3}$ exchanger) may be altered by preconditioning, although the ammonium prepulse experiments with EIPA are consistent with previous results suggesting that a primary mechanism of proton efflux immediately after an acid load is $\mathrm{Na}-\mathrm{H}$ exchange. Third, these data do not define the involvement of other cardioprotective mechanisms in preconditioning, such as ATP-sensitive $\mathrm{K}^{+}$channels or adenosine receptor stimulation $(5,37)$.

The technique of employing a shift reagent to measure intracellular sodium has inherent limitations. The low level of intracellular sodium under baseline conditions makes resolution and quantification of the intracellular resonance difficult and subject to greater error. However, the rise in $\mathrm{Na}_{\mathrm{i}}$ during ischemia improved resolution of the intracellular sodium resonance and made its measurement more reliable. While changes in the volume of the extracellular compartment that occur during ischemia and reperfusion may have changed the relative concentration of the shift reagent in the extracellular space, resulting in a change in chemical shift, the absence of significant changes in these chemical shifts suggests that concentration changes of the shift reagent in the extracellular space were minimal. Furthermore, because the cell membrane is impermeable to the shift reagent (19), changes in extracellular concentration should not have altered the measurement of $\mathrm{Na}_{\mathrm{i}}$. Finally, changes in lineshape of the intracellular resonances were observed and may have been due to spectral processing techniques or inherent changes in the intracellular sodium environment. The integration algorithms were therefore chosen without assumption of either a Lorentzian or Gaussian lineshape and should represent accurately the resonance intensity. However, potentially different intrinsic changes in the intracellular and extracellular com- partments between the groups cannot be excluded as a factor in the measurement of $\mathrm{Na}_{\mathrm{i}}$.

Conclusion. Ischemic preconditioning results in a rapid increase in $\mathrm{Na}_{\mathrm{i}}$ at the onset of global ischemia and a rapid decrease on reperfusion, consistent with activation of mechanisms that enhance sodium transport across the sarcolemma under these conditions. Greater acidification of preconditioned hearts in response to a $\mathrm{NH}_{4} \mathrm{Cl}$ prepulse is consistent with increased inward $\mathrm{NH}_{4}{ }^{+}$flux via the $\mathrm{Na}-\mathrm{K}-2 \mathrm{Cl}$ cotransporter flux after preconditioning, whereas more rapid recovery from acidosis, which is inhibited by EIPA, indicates that proton efflux in preconditioned hearts is increased primarily by stimulation of $\mathrm{Na}-\mathrm{H}$ exchange. In combination with data showing reduced intracellular acidification during ischemia, these data support the postulate that a significant beneficial effect of ischemic preconditioning results from activation of the $\mathrm{Na}-\mathrm{H}$ exchanger and/or $\mathrm{Na}-\mathrm{K}-2 \mathrm{Cl}$ cotransporter before ischemia.

\section{Acknowledgments}

This work was supported by grants to Dr. Schaefer from the National Institutes of Health (HL-02131) and the California Affiliate of the American Heart Association (93-231), and a training grant to Dr. Ramasamy from the National Institutes of Health (HL-07682.)

\section{References}

1. Murry, C. E., V. J. Richard, K. A. Reimer, and R. B. Jennings. 1990. Ischemic preconditioning slows energy metabolism and delays ultrastructural damage during a sustained ischemic episode. Circ. Res. 66:913-931.

2. Li, G. C., J. A. Vasquez, K. P. Gallagher, and B. R. Lucchesi. 1990. Myocardial protection with preconditioning. Circulation. 82:609-619.

3. Schott, R. J., S. Rohmann, E. R. Braun, and W. Schaper. 1990. Ischemic preconditioning reduces infarct size in swine myocardium. Circ. Res. 66:11331142.

4. Kida, M., H. Fujiwara, M. Ishida, C. Kawai, M. Ohura, I. Miura, and Y. Yabuuchi. 1991. Ischemic preconditioning preserves creatine phosphate and intracellular pH. Circulation. 84:2495-2503.

5. Liu, G. S., J. Thornton, D. M. VanWinkle, A. W. H. Stanley, R. A. Olsson, and J. M. Downey. 1991. Protection against infarction afforded by preconditioning is mediated by $A_{1}$ adenosine receptors in rabbit heart. Circulation. 84:350-356.

6. Gross, G. J., and J. A. Auchampach. 1992. Blockade of ATP-sensitive potassium channels prevents myocardial preconditioning in dogs. Circ. Res. 70:223-233.

7. Ytrehus, K., Y. Liu, and J. M. Downey. 1994. Preconditioning protects ischemic rabbit heart by protein kinase C activation. Am. J. Physiol. 266:H1145H1152.

8. Liu, Y., K. Ytrehus, and J. M. Downey. 1994. Evidence that translocation of protein kinase $\mathrm{C}$ is a key event during ischemic preconditioning of rabbit myocardium. J. Mol. Cell. Cardiol. 26:661-668.

9. Schaefer, S., L. J. Carr, E. Prussel, and R. Ramasamy. 1995. Effects of glycogen depletion on ischemic injury in the isolated rat heart: insights into preconditioning. Am. J. Physiol. 268:H935-H944.

10. Schaefer, S., L. J. Carr, U. Kreutzer, and T. Jue. 1993. Myocardial adaptation during acute hibernation: mechanisms of phosphocreatine recovery. Cardio vasc. Res. 27:2044-2051.

11. Rosalski, S. B. 1967. An improved procedure for serum creatine phosphokinase determination. J. Lab. Clin. Med. 69:696-701.

12. Shell, W. E., J. K. Kjekshus, and B. E. Sobel. 1971. Quantitative assessment of the extent of myocardial infarction in the conscious dog by means of analysis of serial changes in serum creatine phosphokinase activity. J. Clin. Invest. $50: 2614$.

13. Kost, G. J. 1990. pH standardization for phosphorus-31 magnetic resonance heart spectroscopy at different temperatures. Magn. Reson. Med. 14:496506.

14. Grace, A. A., H. L. Kirschenlohr, J. C. Metcalfe, G. A. Smith, P. I. Weissberg, E. J. Cragoe, and J. I. Vandenberg. 1993. Regulation of intracellular $\mathrm{pH}$ in the perfused heart by external $\mathrm{HCO}-$ and $\mathrm{Na}+-\mathrm{H}+$ exchange. Am. J. Physiol. 265:H289-H298.

15. O'Donnell, M. E., and N. E. Owen. 1991. Sodium cotransport in vascular smooth muscle cells. Blood Vessels 28:138-146. 
16. O'Grady, S. M., H. C. Palfrey, and M. Field. 1987. Characteristics and functions of $\mathrm{Na}-\mathrm{K}-2 \mathrm{Cl}$ cotransport in epithelial tissues. Am. J. Physiol. 253:C177C192.

17. Haas, M. 1989. Properties and diversity of (Na-K-Cl) cotransporters Annu. Rev. Physiol. 51:443-457.

18. Scholz, W., U. Albus, W. Linz, P. Martorana, H. J. Lang, and B. A. Scholkens. 1992. Effects of $\mathrm{Na}^{+} / \mathrm{H}^{+}$exchange inhibitors in cardiac ischemia. $J$. Mol. Cell. Cardiol. 24:731-740.

19. Steenbergen, C., M. E. Perlman, R. E. London, and E. Murphy. 1993. Mechanism of preconditioning: ionic alterations. Circ. Res. 72:112-125.

20. Liu, H., S. Anderson, and P. Cala. 1994. Effects of ischemic preconditioning on myocardial intracellular $\mathrm{pH}, \mathrm{Na}$ and $\mathrm{Ca}$ in newborn rabbit hearts. $J$. Am. Coll. Cardiol. 23:236A. (Abstr.)

21. Klein, J. D., P. B. Perry, and C. O'Neill. 1993. Regulation of cell volume of $\mathrm{Na}^{+}-\mathrm{K}^{+}-2 \mathrm{Cl}^{-}$cotransport in vascular endothelial cells: role of protein phosphorylation. J. Membr. Biol. 132:243-252.

22. Lytle, C., and B. Forbush. 1992. The Na-K-Cl cotransport protein of shark rectal gland. II. Regulation by direct phosphorylation. J. Biol. Chem. 267:2543825443.

23. Pewitt, E. B., R. S. Hegde, M. Haas, and H. C. Palfrey. 1990. Th regulation of $\mathrm{Na} / \mathrm{K} / 2 \mathrm{Cl}$ cotransport and bumetanide binding in avian erythrocytes by protein phosphorylation and dephosphorylation. J. Biol. Chem. 265:2074720756.

24. O'Donnell, M. E. 1991. Endothelial cell sodium-potassium-chloride cotransport. Evidence of regulation by $\mathrm{Ca} 2+$ and protein kinase $C$. J. Biol. Chem 266:11559-11566

25. Cala, P. M. 1990. Principles of cell volume regulation: ion flux pathways and the roles of anions. In Chloride Channels and Carriers in Nerve, Muscle, and Glial Cells. F. J. Alvenez-Lelfmans and J. M. Russell, editors. Plenum Publishing, New York 67-81.

26. Igarashi, P., M. I. Freed, M. B. Ganz, and R. F. Reilly. 1992. Effects of chronic metabolic acidosis on $\mathrm{Na}^{+}-\mathrm{H}^{+}$exchangers in LLC-PK 1 renal epithelial cells. Am. J. Physiol. 263:F83-F88.

27. Saxena, R., B. A. Saksa, A. P. Fields, and M. B. Ganz. 1993. Activation of $\mathrm{Na} / \mathrm{H}$ exchanger in mesangial cells is associated with translocation of PKC isoforms. Am. J. Physiol. 265:F53-F60.

28. Piwnica-Worms, D., R. Jacob, N. Shigeto, C. R. Horres, and M. Lieberman. 1986. $\mathrm{Na} / \mathrm{H}$ exchange in cultured chick heart cells: secondary stimulation of electogenic transport during recovery from intracellular acidosis. J. Mol. Cell. Cardiol. 18:1109-1116.
29. Cala, P. M., and H. Maldonado. 1994. $\mathrm{pH}$ regulatory $\mathrm{Na} / \mathrm{H}$ exchange by Amphiuma red blood cells. J. Gen. Physiol. 103:1035-1054.

30. Bak, M., and J. S. Ingwall. 1991. Increased activity of $\mathrm{Na}+/ \mathrm{H}+$ exchange system in myocardium from hyperthyroid rats. Soc. Magn. Reson. Med. 1190. (Abstr.)

31. Buser, P. T., J. Wikman-Coffelt, S. T. Wu, N. Derugin, W. W. Parmley, and C. B. Higgins. 1990. Postischemic recovery of mechanical performance and energy metabolism in the presence of left ventricular hypertrophy. Circ. Res. 66:735-746.

32. Tani, M., and J. R. Neely, 1989. Role of intracellular $\mathrm{Na}^{+}$and $\mathrm{Ca}^{2+}$ overload and depressed recovery of ventricular function of reperfused ischemic rat hearts. Circ. Res. 65:1045-1056.

33. Drewnowska, K., and C. M. Baumgarten. 1991. Regulation of cellular volume in rabbit ventricular myocytes: bumetanide, chlorothiazide, and ouabain. Am. J. Physiol. 260:C122-C131.

34. Mitani, A., and M. J. Shattock. 1992. Role of Na-activated K channel, $\mathrm{Na}-\mathrm{K}-\mathrm{Cl}$ cotransport, and Na-K pump in [K] e changes during ischemia in the rat heart. Am. J. Physiol. 263:H333-H340.

35. Dickinson, C. Z., S. E. Anderson, and P. M. Cala. 1991. Bumetanide inhibits sodium efflux in reperfused myocardium. FASEB J. (Fed. Am. Soc. Exp. Biol.) 5:A1049. (Abstr.)

36. Ramasamy, R., P. Zhao, W. L. Gitomer, A. D. Sherry, and C. R. Malloy. 1992. Determination of chloride potential in perfused rat hearts by nuclear magnetic resonance spectroscopy. Am. J. Physiol. 263:H1958-H1962.

37. Grover, G. J., P. G. Sleph, and S. Dzwonczyk. 1992. Role of myocardial ATP-sensitive potassium channels in mediating preconditioning in the dog heart and their possible interaction with adenosine A1-receptors. Circulation. 86:13101316

38. Wallert, M. A., and O. Frohlich. 1992. $\alpha 1$-adrenergic stimulation of NaH exchange in cardiac myocytes. Am. J. Physiol. 263(32):C1096-C1102.

39. Pike, M. M., C. S. Luo, M. D. Clark, K. A. Kirk, M. Kitakaze, M. C. Madden, E. J. Cragoe, and G. M. Pohost. 1993. NMR measurements of $\mathrm{Na}+$ and cellular energy in ischemic rat heart: role of $\mathrm{Na}^{+}-\mathrm{H}^{+}$exchange. Am. J. Physiol. 256:H2017-H2026.

40. Rubin, Y., and G. Navon. 1993. Inhibition of sodium influx and improved preservation of rat hearts during hypothermic ischemia by furosemide and bumetanide: a ${ }^{23} \mathrm{Na}$ - and ${ }^{31} \mathrm{P}-\mathrm{NMR}$ study. J. Mol. Cell. Cardiol. 25:1403-1411.

41. Weiss, R. G., C. de Albuquerque, O. Chacko, and G. Gerstenblith. 1993. Reduced glycogenolysis rather than glycogen depletion contributes to decreased lactate accumulation after preconditioning. Circulation. I-379 (Abstr.) 